\title{
Influence of Lipid Transport System Gene Polymorphism on the Dyslipidemia and Coronary Lesions in Patients with Unstable Angina
}

\author{
Aziz S. Eshpulatov; S.U. Hashimov; Alexander B. Shek, PhD, ScD; \\ Ravshanbek D. Kurbanov, $\mathrm{PhD}, \mathrm{ScD}$ \\ The Republican Specialized Center of Cardiology \\ Tashkent, Uzbekistan
}

\begin{abstract}
The purpose of this study was to identify the features of lipid metabolism and coronary lesions in view of the combined carrier of the $\varepsilon 4$ allele of APOE $\varepsilon 2 / \varepsilon 3 / \varepsilon 4$ polymorphism and the S2 allele of APOC3SstI polymorphism in UA patients.

Materials and Methods: The study included 141 Uzbek patients with UA class IIB (Braunwald E. et al., 1989) who had coronary atherosclerosis of varying degrees, according to coronary angiography. The control group consisted of 50 healthy, agematched, randomly selected Uzbek persons without clinical and instrumental signs of CHD according to the exercise test. Coronary angiography was performed using Allura CV-20 (Philips, Netherlands). Genotyping of the APOE $(\varepsilon 2 / \varepsilon 3 / \varepsilon 4)$ gene polymorphism and the APOC3 (SstI) gene polymorphism was performed by the PCR-RFLP method.

Results: Our analysis revealed a significant prevalence of carriers of the $\mathrm{S} 2$ allele of APOC3SstI polymorphism and carriers of the $\varepsilon 4$ allele of APOE $\varepsilon 2 / \varepsilon 3 / \varepsilon 4$ polymorphism among UA patients compared to healthy ethnic Uzbeks. A combination of these two "damaging" alleles was observed in $26.2 \%$ of UA patients, which was accompanied by significantly higher blood levels of TC and LDL-C $(P<0.05)$, a higher APOB/APOAI ratio $(P<0.05)$, and a lower level of HDL-C $(P<0.05)$. According to coronary angiography, a three-vessel lesion and more significantly predominated among these UA patients (OR: $2.25,95 \%$ CI 1.05-4.84, $\chi^{2}$ 3.66, $P<0.05$ ). (Int J Biomed. 2015;5(4):188-191.)
\end{abstract}

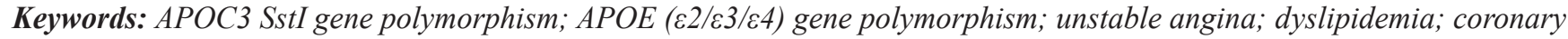
lesions.

\section{Abbreviations}

CHD, coronary heart disease; TC, total cholesterol; TG, triglycerides; LDL-C, low density lipoprotein cholesterol; HDL-C, high density lipoprotein cholesterol; AI, atherogenic index; (APOAI), apolipoprotein A-I; (APOB), apolipoprotein B; APOC3, apolipoprotein C-III; APOE, apolipoprotein E; LP(a), lipoprotein(a); FG, fasting glucose.

\section{Introduction}

Multiple genetic, experimental, clinical, and epidemiological studies clearly indicate the primary role of the lipid metabolism in the development and progression of atherosclerosis and coronary heart disease (CHD). In this connection, of great interest is the study of genes involved in the regulation of transport and metabolism in blood plasma lipids [1-3]. Among the genes under consideration for involvement

*Corresponding author: Aziz S. Eshpulatov. The Republican Specialized Center of Cardiology, Tashkent, Uzbekistan. E-mail: dr.azizbek84@mail.ru in the risk of $\mathrm{CHD}$, most important are genes encoding apolipoproteins A, B, C, E [4-9], whose polymorphic variants have been studied in detail, including in our studies. Earlier we have shown a high incidence of coronary revascularization within one year in patients with coronary artery disease who were carriers of the $\varepsilon 4$ allele of the APOE gene [10-11], as well as a reliable relationship between the carriage of the S2 allele of APOC3SstI polymorphism, an elevated plasma TG level, and a high frequency of coronary artery lesions [12]. The above-mentioned data determined our interest in studying the effect of the combined carriage of "damaging" alleles of these genes on lipid metabolism and the degree of coronary lesions in patients with unstable angina (UA). 
The purpose of this study was to identify the features of lipid metabolism and coronary lesions in view of the combined carrier of the $\varepsilon 4$ allele of APOE $\varepsilon 2 / \varepsilon 3 / \varepsilon 4$ polymorphism and the $\mathrm{S} 2$ allele of APOC3SstI polymorphism in UA patients.

\section{Materials and Methods}

The study included 141 Uzbek patients with UA class IIB (Braunwald E. et al., 1989) who had coronary atherosclerosis of varying degrees, according to coronary angiography. The control group consisted of 50 healthy, age-matched, randomly selected Uzbek persons without clinical and instrumental signs of CHD according to the exercise test.

Exclusion criteria were myocardial infarction (MI) within previous 3 months, diabetes mellitus requiring insulin treatment, arterial hypertension (BP $>159 / 99 \mathrm{mmHg}$ ), hypotension (blood pressure $<100 / 60 \mathrm{mmHg}$ ), atrial fibrillation and life-threatening ventricular arrhythmias, valvular heart disease, long time treatment with lipid-lowering drugs and ACE inhibitors, chronic heart failure (NYHA FC $>$ II), chronic renal and hepatic failure.

All patients underwent the following examinations: assessment of traditional risk factors (high blood pressure, smoking, body mass index, diabetes), physical examination; clinical and biochemical laboratory methods, 12-lead ECG, echocardiography and assessment of the thickness of the intima-media of the carotid arteries (IMT), treadmill test, and coronary angiography.

Blood samples were obtained in the morning after a $12 \mathrm{~h}$ overnight fast. TC, LDL-C, HDL-C, TG, ALT, AST, CPK, APOAI, APOB, LP(a), hsCRP, fibrinogen, fasting glucose , ESR, WBC were determined in plasma using "Daytona» analyzer (RANDOX, Ireland).

Coronary angiography was performed using Allura CV20 (Philips, Netherlands). To assess the degree of narrowing of vessels, a visual assessment was used with the following characteristics: normal coronary artery, changing contours of artery without determining the degree of stenosis, narrowing < $50 \%$ of the luminal diameter, narrowing of $51-75 \%, 76-95 \%$, $95-99 \%$ (subtotal occlusion), and 100\% (total occlusion). Narrowing of the luminal diameter $>50 \%$ was considered significant, $<50 \%$ hemodynamically insignificant.

We isolated DNA from whole blood using a set of Diatom $^{\mathrm{TM}}$ DNA Prep 200. Genotyping of the APOE $(\varepsilon 2 / \varepsilon 3 / \varepsilon 4)$ gene polymorphism and the APOC3 (SstI) gene polymorphism was performed by the PCR-RFLP method using Applied Biosystems Geneamp PCR Systems 2700 and 9700 (USA) at the Institute of Genetics and Plant Experimental Biology and the Republican Specialized Center of Cardiology. PCR amplification was carried using "SibEnzim" kits (Russia).

The sequence primers for APOC3 gene were used according to AR Bandegi et al. [13].

ApoC3 F: 5 '- GGT GACCGATGGCTTCAG TTC CCT GA-3' ApoC3 R: 5'-CAGAAG GTG GAT AGAGCGCTG GCC T-3 '.

PCR products were digested with 15 units of SstI enzyme for a minimum of $3 \mathrm{~h}$ at $37^{\circ} \mathrm{C}$. The resulting fragments were separated according to their size by electrophoresis on $8 \%$ nondenaturing polyacrylamide gel. The alleles lacking the restriction site were designated as $\mathrm{S} 1$, while those containing the SstI site were designated as $\mathrm{S} 2$.

The sequence primers for APOE gene were used according to P.R. Wenham [14].

ApoE F: 5'-TCCAAGGAGCTGCAGGCGGCGCA3 ‘

ApoE R: 5'-ACAGAATTCGCCCCGGCCTGGTACACTGCCA3 ‘

The amplified product was digested with Hhal restriction enzyme. Each of the isoforms was distinguished by a Nigue combination of Hhal fragment sizes that enabled unambiguous typing of all homo-zygotic and heterozygotic combinations.

$\varepsilon 3 / \varepsilon 3$ (91, 48 bp), $\varepsilon 3 / \varepsilon 2$ (91, 81, 48 bp) and $\varepsilon 3 / \varepsilon 4$ (91, 72, 48 $\mathrm{bp)}$ alleles were genotyped according to restriction fragments.

Basic therapy included anticoagulants (heparin or enoxaparine sodium) in the acute period (100\%), antiplatelet agents $(100 \%)$, beta-blockers (bisoprolol, $100 \%$ ), if necessary, nitrates $(95 \%)$ ) and ACE inhibitors (95\%).

The study was conducted in accordance with ethical principles of the Declaration of Helsinki and approved by the Republican Specialized Center of Cardiology Ethics Committee. Written informed consent was obtained from all participants.

Statistical analysis was performed using a statistical software package, Statistica 6.0. The mean (M) and standard deviation (SD) were calculated. For data with normal distribution, inter-group comparisons were performed using Student's t-test and F-test. The Mann-Whitney (U Test) was used to compare the differences between the two independent groups (for nonparametric data). Chi square $\left(\chi^{2}\right)$ or Fischer's exact test (two sided) was used to compare the association between the genotypes and alleles in relation to the cases, and test for deviation of genotype distribution from HardyWeinberg equilibrium. The odds ratio (OR) and their 95\% confidence intervals (CI) were calculated to estimate the strength of the association. A probability value of $P<0.05$ was considered statistically significant.

\section{Results}

The observed frequency of genotypes of APOE $\varepsilon 2 / \varepsilon 3 / \varepsilon 4$ polymorphism and APOC3SstI polymorphism was in HardyWeinberg equilibrium. There were significantly more carriers of the $\varepsilon 4$ allele of APOE $\varepsilon 2 / \varepsilon 3 / \varepsilon 4$ polymorphism among UA patients $(61.7 \%)$ than in the control group (12\%) (Table 1).

Table 1.

Carrier state of the 84 allele of APOE $\varepsilon 2 / \varepsilon 3 / \varepsilon 4$ polymorphism and the $S 2$ allele of APOC3SstI polymorphism among UA patients and healthy persons of Uzbek nationality

\begin{tabular}{|c|c|c|c|c|}
\hline \multicolumn{2}{|c|}{ Gene polymorphism } & $\begin{array}{l}\text { UA patients } \\
\quad(n=141)\end{array}$ & $\begin{array}{c}\text { Healthy persons } \\
(\mathrm{n}=50)\end{array}$ & $P$ \\
\hline \multirow{2}{*}{$\begin{array}{l}\text { APOE } 2 / \varepsilon 3 / \varepsilon 4 \\
\text { polymorphism }\end{array}$} & \begin{tabular}{|c|} 
Carriers \\
of $\varepsilon 4$ allele \\
\end{tabular} & $87(61.7 \%)$ & $6(12 \%)$ & \multirow{2}{*}{$\begin{array}{c}P<0.001 \\
(\text { OR 11.82; } \\
95 \% \text { CI: } \\
4.7-29.6 ; \\
\chi 2=34.5)\end{array}$} \\
\hline & $\begin{array}{l}\text { Non-carriers } \\
\text { of } \varepsilon 4 \text { allele }\end{array}$ & $54(38.3 \%)$ & $44(88 \%)$ & \\
\hline \multirow{2}{*}{$\begin{array}{l}\text { APOC3SstI } \\
\text { polymorphism }\end{array}$} & \begin{tabular}{|c|} 
Carriers \\
of S2 allele \\
\end{tabular} & $51(36.2 \%)$ & $9(18 \%)$ & \multirow{2}{*}{$\begin{array}{c}P<0.05 \\
\text { (OR 2.58; } \\
95 \% \text { CI: } \\
1.2-5.7 ; \\
\chi 2=4.8 \text { ) }\end{array}$} \\
\hline & $\begin{array}{l}\text { Non-carriers } \\
\text { of S2 allele }\end{array}$ & $90(63.8 \%)$ & $41(82 \%)$ & \\
\hline
\end{tabular}


Among UA patients, a plasma level of APOB in $\varepsilon 4$ allele carriers was significantly higher $(113.9 \pm 26.8 \mathrm{mg} / \mathrm{dl})$ than in non-carriers $(100.3 \pm 20.9 \mathrm{mg} / \mathrm{dl}, P<0.05)$; additionally, the trend towards higher values of TC and LDL-C was observed in $\varepsilon 4$ allele carriers. This confirms the potentially high atherogenic properties of dyslipidemia in $\varepsilon 4$ allele carriers.

There were also significantly more carriers of the S2 allele of APOC3SstI polymorphism among UA patients $(36.2 \%)$ than in the control group (18\%),Table 1. S2 allele carriers have a significantly higher blood level of TG than do non-carriers $(261.2 \pm 113.7 \mathrm{mg} / \mathrm{dL}$ vs. $225.8 \pm 87.3 \mathrm{mg} / \mathrm{dL}$; $P<0.05$ ). At the same time, the average levels of TC, LDL-C, HDL-C, APOAI, APOB, and the ratio of APOB/APOAI did not differ between two groups.

In the next stage of the analysis, we joined the carriers of the $\varepsilon 4$ allele of APOE $\varepsilon 2 / \varepsilon 3 / \varepsilon 4$ polymorphism and carriers of the S2 allele of APOC3SstI polymorphism into Group 1 ( $\mathrm{n}=37 / 26.2 \%)$. The remaining patients (104/73.8\%) constituted Group 2. As shown in Table 2, Group 1 patients had significantly higher TC and LDL-C blood levels than did those in Group $2(238.0 \pm 54.3 \mathrm{mg} / \mathrm{dL}$ vs. $220.6 \pm 39.8,154.7 \pm 51.5$ $\mathrm{mg} / \mathrm{dL}$ vs. $138.8 \pm 37.6 \mathrm{mg} / \mathrm{dL} ; P<0.05$ in both cases). At the same time, Group 1 patients had significantly lower levels of HDL-C versus Group 2 patients $(34.1 \pm 6.3 \mathrm{mg} / \mathrm{dL}$ and $36.8 \pm 6.8 \mathrm{mg} / \mathrm{dL}$, respectively, $\mathrm{P}<0.05$ ). These changes in lipid levels resulted in a significantly higher level of AI in Group 1 patients (6.2 \pm 2.0 vs. $5.2 \pm 1.4$ in Group 2; $P<0.05)$. At the same time, there was no difference in the average level of blood TG between the two groups. Group 1 patients had slightly higher plasma levels of APOB and lower levels of APOAI than did Group 2 patients, which resulted in a significantly higher APOB/APOAI ratio: $0.9 \pm 0.3$ vs. $0.8 \pm 0.2, P<0.05$ (Table. 2 ).

Table 2.

Comparative evaluation of the initial blood biochemical parameters in view of the combined carrier of the 84 allele of APOE $\varepsilon 2 / \varepsilon 3 / \varepsilon 4$ polymorphism and the $S 2$ allele of APOC3SstI polymorphism in UA patients

\begin{tabular}{|l|c|c|c|}
\hline \multicolumn{1}{|c|}{ Values } & $\begin{array}{c}\text { Group 1 } \\
(\mathrm{n}=37)\end{array}$ & $\begin{array}{c}\text { Group 2 } \\
(\mathrm{n}=104)\end{array}$ & $P$ \\
\hline TC, mg/dL & $238.0 \pm 54.3$ & $220.6 \pm 39.8$ & $P<0.05$ \\
\hline TG, mg/dL & $245.9 \pm 95.0$ & $234.7 \pm 93.7$ & $P>0.05$ \\
\hline LDL-Cl, mg/dL & $154.7 \pm 51.5$ & $138.8 \pm 37.6$ & $P<0.05$ \\
\hline HDL-C, mg/dL & $34.1 \pm 6.3$ & $36.8 \pm 6.8$ & $P<0.05$ \\
\hline VLDL-C, mg/dL & $49.2 \pm 19.0$ & $46.9 \pm 18.7$ & $P>0.05$ \\
\hline AI, relative units & $6.2 \pm 2.0$ & $5.2 \pm 1.4$ & $P<0.05$ \\
\hline FG, mmol/L & $5.8 \pm 1.7$ & $5.8 \pm 1.3$ & $P>0.05$ \\
\hline APOA-I, mg/dL & $133.8 \pm 21.3$ & $139.1 \pm 22.2$ & $P>0.05$ \\
\hline APOB, mg/dl & $115.0 \pm 24.9$ & $107.0 \pm 25.7$ & $P>0.05$ \\
\hline APOB/APOA-I & $0.9 \pm 0.3$ & $0.8 \pm 0.2$ & $P<0.05$ \\
\hline LP (a), mg/dL & $30.1 \pm 22.8$ & $34.7 \pm 35.5$ & $P>0.05$ \\
\hline
\end{tabular}

According to the severity of coronary lesions, patients were divided into subgroups with one, two, and three or more multivessel lesions (Table 3). In the most severe subgroup, patients with a three-vessel lesion and more, the patients of Group $1(59.5 \%)$ significantly predominated compared to the patients of Group 2 (39.4\%) $(\mathrm{OR}=2.25,95 \% \mathrm{CI}: 1.05-4.84$; $\chi 2=3.66, P<0.05)$.
Table 3.

Comparative evaluation of the coronary angiography data in the studied patient groups in view of the combined carrier of the 84 allele of $A P O E$ E2/\&3/\&4 polymorphism and the $S 2$ allele of APOC3SstI polymorphism

\begin{tabular}{|l|c|c|c|}
\hline \multicolumn{1}{|c|}{ Variable } & $\begin{array}{c}\text { Group 1 } \\
(\mathrm{n}=37)\end{array}$ & $\begin{array}{c}\text { Group 2 } \\
(\mathrm{n}=104)\end{array}$ & $P$ \\
\hline $\begin{array}{l}\text { Stenosing coronary } \\
\text { atherosclerosis }\end{array}$ & $36(97.3 \%)$ & $89(85.6 \%)$ & $P>0.05$ \\
\hline one-vessel lesion & $7(18.9 \%)$ & $24(23.1 \%)$ & $P>0.05$ \\
\hline two-vessel lesion & $7(18.9 \%)$ & $24(23.1 \%)$ & $P>0.05$ \\
\hline $\begin{array}{l}\text { three- and multi- } \\
\text { vessel lesion }\end{array}$ & $22(59.5 \%)$ & $41(39.4)$ & $P<0.05$ \\
\hline $\begin{array}{l}\text { No angiographic evidence } \\
\text { of coronary artery stenosis }\end{array}$ & $1(2.7 \%)$ & $15(14.4 \%)$ & $P>0.05$ \\
\hline
\end{tabular}

\section{Discussion}

One of the most effective approaches to the study of genetic mechanisms of CHD is the identification of genetic markers of the disease. Such studies provide an opportunity to establish the involvement in CHD pathogenesis of specific candidate genes and on this basis to identify the group of individuals with a high genetic risk of CHD development. A number of epidemiological studies have analyzed the impact of APOE polymorphism on cardiovascular disease. Eichner et al. [15] and Lehtinen et al.[16] suggested that $\varepsilon 4$ allele carriers were particularly predisposed to develop coronary lesions or to possess elevated risk of CAD death. The authors suggest that this could be a consequence of lipoprotein metabolism dysfunction associated with the $\varepsilon 4$ isoform, with elevation of total cholesterol and triglyceride levels [17].

Schiele et al. [18], studying northern European populations with higher cholesterol levels and higher CVD mortality, have also shown higher $\varepsilon 4$ allele presence. Hixson et al. [19] and Ilveskoski et al. [20], studying vascular necropsy alterations, showed more atherosclerotic lesions in $\varepsilon 4$ allele carriers, independent of total cholesterol levels. On the other hand, according to L.M. Lima et al. angiographic studies did not evidence higher CHD risk in $\varepsilon 4$ allele carriers [21]. In the MONICA study [22], a $\varepsilon 4$ allele frequency elevation of 0.01 was associated with a rise in CHD death of 24.5 per 100,000 patients. In a $4 \mathrm{~S}$ study [9], $\varepsilon 4$ allele carriers presented an $80 \%$ higher death risk after myocardial infarction, in comparison with other patients. Lahoz et al. [23] concluded that $\varepsilon 2$ and $\varepsilon 4$ allele presences were associated with higher cardiovascular risk in men. The authors argued that the $\varepsilon 4$ allele determines higher risk partly due to the lipid alterations that it brings on.

The relationship between the SstI polymorphism of APOC 3 and an increased risk of coronary artery disease was confirmed by genetic analysis in the framework of the classic Framingham study [24]. According to our study, a significant prevalence of S2 allele carriers of APOC3SstI polymorphism among UA patients, compared to healthy ethnic Uzbeks, also indicates the presence of an association between this polymorphic gene marker and the risk of CHD progression. The combined carriage of two "damaging" alleles (S2 and 
$\varepsilon 4)$ is one of the factors that increase the risk of atherogenic dyslipidemia and coronary stenosis, which can be a useful additional marker for the assessment of cardiovascular risk and indications for coronary angiography.

\section{Conclusion}

Our analysis revealed a significant prevalence of carriers of the S2 allele of APOC3SstI polymorphism and carriers of the $\varepsilon 4$ allele of APOE $\varepsilon 2 / \varepsilon 3 / \varepsilon 4$ polymorphism among UA patients compared to healthy ethnic Uzbeks. A combination of these two "damaging" alleles was observed in $26.2 \%$ of UA patients, which was accompanied by significantly higher blood levels of TC and LDL-C $(P<0.05)$, a higher APOB/ APOAI ratio $(P<0.05)$, and a lower level of HDL-C $(\mathrm{P}<0.05)$. According to coronary angiography, a three-vessel lesion and more significantly predominated among these UA patients $(\mathrm{OR}=2.25,95 \% \mathrm{CI}: 1.05-4.84 ; \chi 2=3.66, P<0.05)$.

\section{Competing interests}

The authors declare that they have no competing interests.

\section{References}

1. Vinogradova SV. The role of apolipoprotein E gene polymorphism in the development of atherosclerosis (review). Medical Genetics. 2006; 2:3-10 [Article in Russian].

2. Song Y. Stampfer MJ. Liu S. Meta-analysis: apolipoprotein E genotypes and risk for coronary heart disease. Ann Int Med. 2004;141(2):137-47.

3. Davignon J, Cohn JS, Mabile L, Bernier L. Apolipoprotein $\mathrm{E}$ and atherosclerosis: insight from animal and human studies. Clin Chim Acta. 1999; 286:115-43.

4. de Andrade M, Thandi I, Brown S, Gotto A Jr, Patsch W, Boerwinkle E. Relationship of the apolipoprotein E polymorphism with carotid artery atherosclerosis. Am J Hum Genet. 1995; 56:1379-90.

5. Wang CS, McConathy WJ, Kloer HU, Alaupovic P. Modulation of lipoprotein lipase activity by apolipoproteins. J Clin Invest. 1985; 75:384-90.

6. Sacks FM, Alaupovic P, Moye LA, Cole TG, Sussex B, Stampfer MJ, et al. VLDL, apolipoproteins B, CIII, and E, and risk of recurrent coronary events in the Cholesterol and Recurrent Events (CARE) trial. Circulation. 2000;102:1886-92. 7. Alaupovic P, Mack WJ, Knight-Gibson C, Hodis HN. The role of triglyceride-rich lipoprotein families in the progression of atherosclerotic lesions as determined by sequential coronary angiography from a controlled clinical trial. Arterioscler Thromb Vasc Biol. 1997;17(4):715-22.

8. Tsai MY, Ordovas JM. APOC3 mutation, serum triglyceride concentrations, and coronary heart disease. Clin Chem. 2009; 55(7):1274-6.

9. Gerdes LU, Gerdes C, Kervinen K, Savolainen M, Klausen IC, Hansen PS, et al. The apolipoprotein epsilon4 allele determines prognosis and the effect on prognosis of simvastatin in survivors of myocardial infarction: a substudy of the Scandinavian simvastatin survival study. Circulation. 2000; 101(12):1366-71.

10. Bekmetova FM, Kan LE, Hoshimov SU. Kurbanov
RD. Clinical value distribution of polymorphism of the lipidtransport systems genes in patients with unstable angina and coronary heart disease in family history. Eurasian Heart J. 2013; 2:51-59. [Article in Russian].

11. Eshpulatov AS, Hashimov SU, Bekmetova FM, Shek $\mathrm{AB}$, Kurbanov RD. Influence of the SstI polymorphism in the apolipoprotein $\mathrm{C} 3$ gene on the dyslipidemia and coronary lesions in patients with unstable angina. Int J Biomed. 2014; 4(4, Suppl1):15-9.

12. Eshpulatov AS, Hashimov SU, Bekmetova FM, Shek AB, Kurbanov RD. Distribution of gene APO CIII polymorphism in unstable angina patients with three-vessel coronary arteries lesion. Kardioangiologia i Revmatologia. 2014; 7:23-29. [Article in Russian].

13. Bandegi AR, Firoozrai M, Akbari Eidgahi MR, Kokhaei P. SstI Polymorphism of the Apolipoprotein CIII Gene in Iranian Hyperlipidemic Patients: A Study in Semnan Province. Iran J Basic Med Sci. 2011;14(6):506-13.

14. Wenham PR, Price WH, Blundell G. Apolipoprotein E genotyping by one-stagePCR. Lancet.1991;337(8750):1158-9. 15. Eichner JE, Kuller LH, Orchard TJ, Grandits GA, McCallum LM, Ferrell RE, et al. Relation of apolipoprotein E phenotype to myocardial infarction and mortality from coronary artery disease. Am J Cardiol. 1993;71(2):160-5.

16. Lehtinen S, Lehtimaki T, Sisto T, Salenius JP, Nikkila M, Jokela H, et al. Apolipoprotein E polymorphism, serum lipids, myocardial infarction and severity of angiographically verified coronary artery disease in men and women. Atherosclerosis. 1995;114(1):83-91.

17. Utermann G. Apolipoprotein Epolymorphism in health and disease. Am Heart J. 1987;113(2 Pt 2):433-40.

18. Schiele F, De Bacquer D, Vincent-Viry M, Beisiegel U, Enholm C, Evans A, et al. Apolipoprotein E serum concentration and polymorphism in six European countries: the ApoEurope Project. Atherosclerosis. 2000;152(2):475-88. 19. Hixson JE. Apolipoprotein E polymorphisms affect atherosclerosis in young males. Pathobiological Determinants of Atherosclerosis in Youth (PDAY) Research Group. Arterioscler Thromb. 1991;11(5):1237-44.

20. Ilveskoski E, Perola M, Lehtimaki T, Laippala P, Savolainen V, Pajarinen J, et al. Age-dependent association of apolipoprotein E genotype with coronary and aortic atherosclerosis in middle-aged men: an autopsy study. Circulation. 1999;100(6):608-13.

21. Lima LM, Carvalho Md, Ferreira CN, Fernandes AP, Neto $\mathrm{CP}$, Garcia JC, et al. Atheromatosis extent in coronary artery disease is not correlated with apolipoprotein-E polymorphism and its plasma levels, but associated with cognitive decline. Curr Alzheimer Res. 2010;7(6):556-63.

22. The World Health Organization MONICA Project (monitoring trends and determinants in cardiovascular disease): a major international collaboration. WHO MONICA Project Principal Investigators. J Clin Epidemiol. 1988;41(2):105-14. 23. Lahoz C, Schaefer EJ, Cupples LA, Wilson PW, Levy D, Osgood D, et al. Apolipoprotein E genotype and cardiovascular disease in the Framingham Heart Study. Atherosclerosis. 2001;154(3):529-37.

24. Russo GT, Meigs JB, Cupples LA, Demissie S, Otvos JD, Wilson PW, et al. Association of the Sst-I polymorphism at the APOC3 gene locus with variations in lipid levels, lipoprotein subclass profiles and coronary heart disease risk: the Framingham offspring study. Atherosclerosis. 2001; 158(1):173-81. 